\title{
Prior room occupancy increases risk of methicillin-resistant Staphylococcus aureus acquisition
}

\author{
Brett G. Mitchell ${ }^{1,2,6} \mathrm{PhD}$, M.Adv.Prac., BN, DTN \\ Wilhelmine Digney ${ }^{3} \mathrm{BN}$ \\ John K. Ferguson ${ }^{4,5}$ MBBS, DTM\&H, FRACP (Infectious Diseases), FRCPA (Microbiology) \\ ${ }^{1}$ Faculty of Nursing and Health, Avondale College of Higher Education, Wahroonga, NSW 2076, Australia. \\ ${ }^{2}$ School of Nursing, Midwifery and Paramedicine, Australian Catholic University, NSW 2602, Australia. \\ ${ }^{3}$ Launceston General Hospital, Launceston, Tas. 7250, Australia. \\ ${ }^{4}$ Infectious Disease and Microbiology, John Hunter Hospital, Newcastle, NSW 2310, Australia. \\ ${ }^{5}$ School of Medicine, University of Newcastle, NSW 2308, Australia. \\ ${ }^{6}$ Corresponding author. Email: brett.mitchell@avondale.edu.au
}

\begin{abstract}
Background: In Australia, little is known about the risk of acquiring methicillin-resistant Staphylococcus aureus (MRSA) from prior room occupants. The aims of the study are to understand the risk of MRSA acquisition from prior room occupants and to further extend the existing knowledge-base on the role of discharge cleaning in hospitals.

Methods: A non-concurrent cohort study was undertaken in five wards at a 250-bed general hospital in Tasmania, Australia. All admitted patients were screened for MRSA. Weekly screenings for all patients who remained in hospital were undertaken. New MRSA acquisitions were identified. The exposed group were patients whose immediate prior room occupant had MRSA, while the unexposed prior room occupant did not have MRSA.

Results: 6228 patients were at risk of acquiring MRSA, with 237 new MRSA acquisitions equating to an acquisition rate of $3.8 \%$ for each at-risk patient admission. The unadjusted odds ratio for acquiring MRSA when the prior room occupant had MRSA was 2.9 (95\% CI 2.2-3.9). Using logistic regression, exposure to a prior occupant harbouring MRSA remained a significant predictor of subsequent acquisition, after controlling for variables, OR 2.7 (95\% CI 2.0-3.6).

Conclusion: Admission to a room previously occupied by a person with MRSA increased the odds of acquisition for the subsequent patient, independent of other risk factors. It demonstrates the necessity of having effective discharge cleaning practices in place. We believe increased attention to discharge room cleaning in hospitals is required and the reconsideration of additional recommendations for discharge cleaning.
\end{abstract}

Received 21 July 2014, accepted 14 October 2014, published online 10 November 2014

\section{Background}

Internationally, major safety and quality efforts are being made to reduce the harms and risks associated with healthcareassociated infections (HAIs). There are many processes that can be established to reduce the risk of organism transmission in healthcare settings. ${ }^{1}$ These include: adequate levels of hand hygiene compliance, correct application of personal protective equipment, appropriate intravascular device management and optimal levels of environmental cleanliness. Methicillin-resistant Staphylococcus aureus (MRSA) is one of the organisms that is commonly associated with HAIs, and is linked to morbidity and mortality in hospitalised patients. ${ }^{2,3}$

To understand how the environment plays a part in the occurrence of infections, it is important to think beyond the end-point of the infected patient. For example, persons colonised with microorganisms can contaminate a healthcare environment. These microorganisms can subsequently be transferred to other sites, most commonly by the hands of healthcare workers, patients and visitors. ${ }^{4}$ Microorganisms acquired from these sites may then be responsible for infection in other patients. Similarly, infection may occur many months following contamination and subsequent colonisation, often after the patient has been discharged from hospital. ${ }^{5}$ In the past, the roles of inanimate objects in hospital environments (e.g. surfaces and equipment) in the spread of HAIs were regarded as controversial. ${ }^{6}$ However, a large body of evidence now supports the notion that the environment plays a part in microorganism transmission and subsequent infection. ${ }^{7-9}$ Several studies have demonstrated that the persistence of microorganisms in the environment leads to an increased risk 


\section{Implications}

- In Australia, little is known about the risk of acquiring methicillin-resistant Staphylococcus aureus from prior room occupants.

- Admission to a room previously occupied by a person with methicillin-resistant Staphylococcus aureus increases the odds of acquisition for the subsequent patient.

- Increased attention to discharge room cleaning in hospitals is required and the reconsideration of additional recommendations for discharge cleaning.

of acquiring an infection for a patient who is admitted to a room that was previously occupied by a patient colonised or infected with a particular organism. ${ }^{8,10,11}$ These studies, alongside those on the known role of colonisation pressure, demonstrate the potentially important role that the environment plays in infection transmission and prevention.

In Australia, little is known about the risk of acquiring MRSA from prior room occupants. This study explores the risks of MRSA acquisition resulting from prior room occupancy to demonstrate the potential role that the environment plays in organism transmission and infection. The specific aims of the study are to understand the risk of MRSA acquisition from prior room occupants and to further extend the existing knowledge base on the role of discharge cleaning in hospitals.

\section{Methods}

Study design

A non-concurrent cohort study was carried out between 1 January 2011 and 31 December 2012.

\section{Setting and sample}

The study was undertaken in five wards at a 250-bed general hospital in Tasmania. All patients admitted to these wards were included in the study. The five wards under surveillance were medical and surgical wards, as well as one medical admissions unit. These wards consisted of shared rooms and a small number of single rooms. All persons admitted to the wards were screened for MRSA, regardless of risk factors. The MRSA screens consisted of nose, throat and perineum swabs, using pre-moistened swabs with sterile saline $(0.9 \%)$. Weekly screenings for all patients who remained in hospital were also undertaken. The microbiology laboratory performing the testing for the study was an accredited laboratory (National Association of Testing Authorities). Brilliance chromogenic agar (Oxoid, Adelaide, South Australia, Australia) was directly inoculated from the screening swabs. Plates were allowed to warm to room temperature before inoculation and incubation, for a minimum of $20 \mathrm{~h}$ at $37^{\circ} \mathrm{C}$.

The hospital's policy was to instigate contact precautions for any person known to have MRSA colonisation or infection. Persons with a history of MRSA were placed under contact precautions upon admission and housed in single rooms (whenever possible), until the results of the admission screenings were obtained. Compliance with admission screening procedures was monitored by infection control staff throughout the study period, with wards consistently achieving $80 \%$ policy compliance or higher.

\section{Data collection and definitions}

For all participants in the cohort, data were collected from two sources: the clinical coding department and the infection control department. The infection control department provided data on all persons who newly acquired MRSA during the study period. New MRSA acquisitions were defined as instances in which MRSA was identified in any clinical specimen or weekly patient screen obtained $48 \mathrm{~h}$ or more after admission, in patients with no known previous history of MRSA and with negative MRSA admission screen results. If a patient did not have an admission screen undertaken, they were assumed not to have MRSA, unless they had a previous history of MRSA. The data provided by the infection control department were the patient's hospital number, the date of MRSA acquisition (specimen collection date) and the ward and bed number of the patient.

The clinical coding department provided data on all patients admitted to the wards who were under observation. The data provided were admission and discharge dates, patients' hospital numbers, dates of birth, sex, diagnosisrelated groups (DRG), International Classification of Diseases (ICD) codes (Australian, 10th Edition), patient locations during each admission (ward and room number) and patient's history of MRSA (alert status on an electronic system). In the 11 years before the commencement of this study, all patients at the hospital (in-patient and outpatients) who had been identified as having MRSA had electronic alerts placed on their medical records, using an electronic patient information system. The alerts could only be removed by the infection control unit once the patient had three consecutive negative MRSA screens.

A Charlson co-morbidity index score was calculated for each person by using ICD coding data, as is consistent with previously published literature. ${ }^{12}$

\section{Data analysis}

The cohort was divided into two groups: exposed and nonexposed. The exposed group consisted of persons whose immediate prior room occupant had MRSA, whilst the unexposed group included persons whose immediate prior room occupant did not have MRSA. No differentiation was made between single and shared rooms. Patients known to be colonised (on admission or subsequently) were housed in single rooms or were cohorted together in shared bays. Data provided by the infection control department and clinical coding were merged into one Excel database for data cleaning, before being exported into SPSS 21.0, in which analysis was undertaken. 
Differences in the characteristics of patents who acquired MRSA and those who did not were explored by using Chisquared tests and Fisher's exact tests. The proportions of patients acquiring MRSA were assessed by exposure status, using Chi-squared tests, and medians were compared by using the Mann-Whitney $U$-test. Fig. 1 provides a summary of the cohort. We incorporated all predictors in the univariate analysis at the $P<0.1$ level into a multivariate logistic regression model. To calculate the cut-off points for age and length of stay in the logistic regression model, a receiver operating characteristic (ROC) curve was used. Odds ratios and $95 \%$ confident intervals were calculated, in addition to the Hosmer-Lemshow goodness-of-fit.

\section{Results}

During the study period, 6228 patients were at risk of acquiring MRSA, as they had never had MRSA. Of these, 884 $(14.2 \%)$ were admitted to rooms where the prior occupants had MRSA, with 74 (8.3\%) subsequently acquiring MRSA. Conversely, of the 5344 patients admitted to rooms where the prior occupants did not have MRSA, 163 (1.3\%) subsequently acquired MRSA. The unadjusted odds ratio for acquiring MRSA when the prior room occupant had MRSA was 2.90 (95\% CI 2.18-3.86). The total number of new MRSA acquisitions during the study period was 237 , equating 1.08 acquisitions per 1000 bed days (95\% CI $0.95-1.23)$ or an acquisition rate of $3.8 \%$ for each at-risk patient admission. Further patient demographics are provided in Table 1. Significantly, patients who had a cerebral vascular accident, dementia, were admitted to Wards A and B, or who stayed in hospital for more than 10 days were more likely to acquire MRSA than others. Conversely, patients diagnosed with cancer were less likely to acquire MRSA.

In the logistic regression model, exposure to a prior occupant harbouring MRSA remained a significant predictor of subsequent acquisition, after controlling for variables such

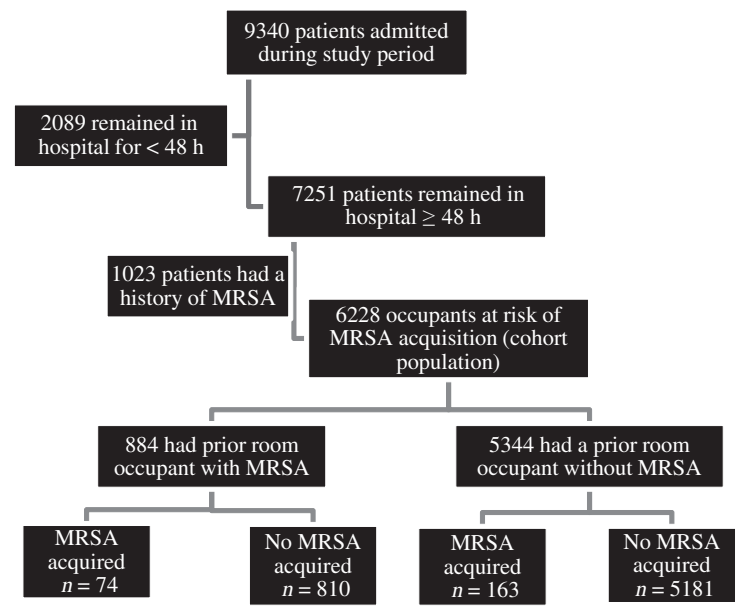

Fig. 1. Overview of the study cohort. MRSA, methicillin-resistant Staphylococcus aureus. as age, sex, comorbidities, length of stay and ward (Table 2), OR 2.71 (95\%CI 2.03-3.63).

\section{Discussion}

The main findings of this study indicate that prior room occupancy by a patient with MRSA was significantly associated with elevated risk of acquiring MRSA in the next person occupying the room. This risk was present despite infection prevention and control measures taken for patients with MRSA. The measures used during the study period to prevent and control the spread of MRSA included the instigation of contact precautions, measures to improve hand hygiene compliance, weekly MRSA screening of inpatients and enhanced terminal cleaning.

The use of contact precautions was conducted in a manner consistent with national recommendations ${ }^{13}$ including: the wearing of gloves and aprons or gowns, the isolation of patients in single rooms when possible and cohorting when not, and the use of patient-dedicated equipment. Rooms were cleaned at least daily with detergent and upon discharge, and hydrogen peroxide (HP) was used for discharge cleans. It is possible, however, that non-compliance with some of these measures contributed to the transmission of MRSA between patients, independent of any prior room exposure.

A formal evaluation of the use of HP in terminal cleaning occurring at the same time as this study, suggested that the introduction of HP is associated with a reduction in MRSA acquisition and MRSA contamination, compared with the use of a detergent. ${ }^{14}$ However, it is important to note that despite the significant improvements made by using HP, MRSA could still be cultured from $18.8 \%$ of rooms following a discharge clean. ${ }^{14}$ This is consistent with other published evidence indicating environmental contamination of room surfaces and equipment with MRSA, including instances where enhanced measures were taken to reduce its presence. ${ }^{15-19}$

Hand hygiene compliance was monitored during the study period, consistent with a national ' 5 moments for hand hygiene' initiative being undertaken at the time. ${ }^{20}$ Although hand hygiene compliance rose during this time, from $66.9 \%$ (95\% CI 64.9\% to $68.6 \%$ ) in early 2010 to $70.4 \%$ (95\% CI 68.3 to $72.5 \%$ ) at the end of 2012 , the increase was not significant. ${ }^{21}$ It is likely that lack of hand hygiene compliance was a contributory factor to new MRSA acquisition in this study. However hand hygiene compliance cannot explain the impact of room occupancy location on the MRSA acquisition rate.

Our findings on the increased risk of acquiring multiresistant organisms are consistent with the findings of other studies. ${ }^{10,22-24}$ Our acquisition rate of $3.8 \%$ for each at-risk patient admission is higher than that reported in a Scottish $(1.3 \%)^{25}$ and German $(0.3 \%)^{26}$ studies. Contrary to the findings of a study undertaken by Huang et al. ${ }^{10}$ we did not find that age was an independent risk factor for acquisition. Conversely, studies exploring the risk of prior room occupancy on vancomycin-resistant Enterococcus, Clostridium difficile infection and extended spectrum 
Table 1. Cohort characteristics

Bold font indicates statistically significant at the 0.05 level. AMU, Acute Medical Admissions Unit; CHF, congestive heart failure; CVA, cerebral vascular accident; MI, myocardial infarction; MRSA, methicillin-resistant Staphylococcus aureus; s.d., standard deviation; VD, vascular disease

\begin{tabular}{|c|c|c|c|c|c|c|}
\hline Characteristic & $\begin{array}{c}\text { New MRSA } \\
\text { acquisition } \\
n=237\end{array}$ & $\begin{array}{c}\text { No MRSA } \\
\text { acquisition } \\
n=5991\end{array}$ & $P$-value & $\begin{array}{c}\text { Patient's room's } \\
\text { previous occupant } \\
\text { had MRSA } \\
n=884\end{array}$ & $\begin{array}{c}\text { Patient's room's } \\
\text { previous occupant } \\
\text { did not have MRSA } \\
n=5344\end{array}$ & $P$-value \\
\hline Age (median) & 73 & 68 & $<0.001^{\mathrm{A}}$ & 80 & 83 & $<\mathbf{0 . 0 0 0}^{\mathrm{A}}$ \\
\hline \multicolumn{7}{|l|}{ Sex } \\
\hline Male & 123 & 3068 & \multirow[t]{2}{*}{0.835} & 441 & 2750 & \multirow[t]{2}{*}{0.386} \\
\hline Female & 114 & 2923 & & 443 & 2594 & \\
\hline \multicolumn{7}{|l|}{ Charlson score } \\
\hline$<1$ & 165 & 4096 & \multirow[t]{2}{*}{0.684} & 594 & 3667 & \multirow[t]{2}{*}{0.399} \\
\hline$\geq 1$ & 72 & 1895 & & 290 & 1677 & \\
\hline \multicolumn{7}{|l|}{ Comorbidity diagnosis } \\
\hline Acute MI present & $4(2 \%)$ & $91(2 \%)$ & 0.835 & $16(2 \%)$ & $79(1 \%)$ & 0.456 \\
\hline CHF present & $4(2 \%)$ & $141(2 \%)$ & 0.505 & $28(3 \%)$ & $117(2 \%)$ & 0.074 \\
\hline Peripheral VD present & $0(0 \%)$ & $2(<0.1 \%)$ & 0.925 & $0(0 \%)$ & $2(0 \%)$ & 0.736 \\
\hline CVA present & $27(11 \%)$ & $144(2 \%)$ & $<0.001$ & $31(4 \%)$ & $140(3 \%)$ & 0.135 \\
\hline Dementia present & $4(2 \%)$ & $14(<0.1 \%)$ & 0.004 & $8(1 \%)$ & $10(0 \%)$ & 0.002 \\
\hline Pulmonary disease present & $8(3 \%)$ & $230(4 \%)$ & 0.715 & $41(5 \%)$ & $197(4 \%)$ & 0.172 \\
\hline Connective tissue disorder present & $0(0 \%)$ & $16(<0.1 \%)$ & 0.537 & $3(0 \%)$ & $13(0 \%)$ & 0.402 \\
\hline Peptic ulcer present & $1(0 \%)$ & $25(<0.1 \%)$ & 0.636 & $4(0 \%)$ & $22(0 \%)$ & 0.515 \\
\hline Liver disease present & $0(0 \%)$ & $12(<0.1 \%)$ & 0.628 & $1(0 \%)$ & $11(0 \%)$ & 0.475 \\
\hline Diabetes present & $1(0.1 \%)$ & $36(<0.1 \%)$ & 0.725 & $6(1 \%)$ & $31(1 \%)$ & 0.724 \\
\hline Diabetes complications present & $0(0 \%)$ & $7(<0.1 \%)$ & 0.762 & $0(0 \%)$ & $7(1 \%)$ & 0.342 \\
\hline Paraplegia present & $0(0 \%)$ & $4(<0.1 \% 0)$ & 0.856 & $1(0 \%)$ & $3(0 \%)$ & 0.458 \\
\hline Renal disease present & $2(1 \%)$ & $9(<0.1 \% 0)$ & 0.063 & $2(0 \%)$ & $9(0 \%)$ & 0.477 \\
\hline Cancer present & $16(7 \%)$ & $931(16 \%)$ & $<0.001$ & $115(13 \%)$ & $832(16 \%)$ & 0.050 \\
\hline Metastatic cancer present & $5(2 \%)$ & $227(4 \%)$ & 0.181 & $34(4 \%)$ & $198(4 \%)$ & 0.837 \\
\hline Severe liver disease present & $0(0 \%)$ & $4(<0.1 \%)$ & 0.856 & $0(0 \%)$ & $4(0 \%)$ & 0.542 \\
\hline \multicolumn{7}{|l|}{ Length of stay } \\
\hline Median & 20 & 5 & \multirow[t]{2}{*}{$<0.001^{\mathrm{A}}$} & 6 & 6 & \multirow[t]{2}{*}{$0.02^{\mathrm{A}}$} \\
\hline Mean (s.d.) & $28.7(30.3)$ & $8.5(9.7)$ & & $10.8(13.0)$ & $9.1(11.7)$ & \\
\hline \multicolumn{7}{|l|}{ Ward admitted to } \\
\hline $\mathrm{A}$ & 33 & 1134 & 0.053 & 174 & 993 & 0.437 \\
\hline B & 21 & 1210 & $<0.001$ & 119 & 1112 & $<0.001$ \\
\hline Medical or oncology & 66 & 1700 & 0.860 & 220 & 1546 & 0.013 \\
\hline Stroke ward & 96 & 821 & $<0.001$ & 199 & 718 & $<0.001$ \\
\hline AMU & 21 & 1126 & $<0.001$ & 172 & 975 & 0.389 \\
\hline
\end{tabular}

${ }^{\mathrm{A}}$ Mann-Whitney $U$-test.

Table 2. Independent predictors of MRSA acquisition by included in the final multiple logistic regression model

Age was included in the model, but was not found to be a significant, odds ratio 5.3 (95\% CI 0.7-38.4). Length of stay variable was determined using the receiver operating characteristic curve. CI, confidence interval; MRSA, methicillin-resistant Staphylococcus aureus

\begin{tabular}{lcr}
\hline Model & Odds ratio $(95 \% \mathrm{CI})$ & $P$ \\
\hline Prior room occupant had MRSA & $2.7(2.0-3.6)$ & $<0.01$ \\
Length of stay $(>2$ days) & $9.7(3.6-26.4)$ & $<0.01$ \\
Cerebral vascular accident & $4.2(2.7-6.6)$ & $<0.01$ \\
Dementia & $4.6(1.5-14.5)$ & 0.01 \\
Cancer & $0.5(0.3-0.8)$ & 0.01 \\
\hline
\end{tabular}

$\beta$-lactamase-producing Gram-negative bacteria did not find age to be an independent risk factor of acquisition. ${ }^{22-24}$

We identified a difference in the lengths of stay between patients who had newly acquired MRSA and those who had not. However, no conclusions regarding MRSA causing increased length of stay should be drawn from these data, as our study was not designed to evaluate the effects of MRSA acquisition on length of stay, and attempting to do so would not be possible without introducing time-dependent bias. ${ }^{27,28}$ The difference in length of stay in persons who acquired MRSA compared with those who did not, could potentially be due to reverse causality, i.e. the longer a person remained in the hospital, the more likely they were to acquire MRSA.

In our study, there was no difference between patients who acquired MRSA and those who did not in the calculated Charlson comorbidity index. However, upon further exploration of individual co-morbidities, some differences were found in patients with current medical histories of cancer, cerebral vascular accidents or dementia. Those with cancer were less likely to acquire MRSA than those without. This could potentially be explained by the hospital policy of housing the majority of these patients (medical and oncology), 
(Table 1) in a ward away from MRSA patients, and the specific designation of a section of this ward as 'MRSA free', meaning that no patient with MRSA could be placed in the protected ward area. This approach could be considered successful, given that this ward was not associated with an increased risk of MRSA acquisition. Conversely, those wards with patients with dementia or a cerebral vascular accident were more likely to acquire MRSA than those without. Possible explanations for this include the fact that cerebral vascular accident patients require more nursing care and therefore are at an increased risk of MRSA transmission via healthcare workers' hands. Also, these patients are likely to be less mobile than others, and therefore in frequent contact with potentially contaminated near-patient equipment. With regard to patients with dementia, a study by Lasseter et $a l .^{29}$ suggests that crossinfection through staff caring for dependent residents with dementia may spread MRSA within care home environments. It is possible that this explanation also applies to our findings.

\section{Conclusion}

Our study demonstrates the increased odds of patients acquiring MRSA when they stay in rooms whose prior occupants carried MRSA, independent of other risk factors. As such, it demonstrates the necessity of having effective cleaning practices in place, particularly once patients have been discharged. We believe that there is a need for increased attention to discharge room cleaning in hospitals and the reconsideration of additional recommendations for terminal cleaning. ${ }^{13}$ As we have shown in a previous study, if disinfectants are not capable of eliminating all microbial contamination, we may need consider the use of advanced cleaning technologies, in addition to those already employed. Directions for future research in this area include the need to explore new approaches for cleaning and isolation, including methods aimed at improving compliance with existing approaches. Similarly, a better understanding of the role that MRSA colonisation versus infection in prior room occupants has on subsequent transmission would assist in policy-setting for prioritising single and isolation rooms, and would improve our understanding of transmission pathways.

\section{Funding}

No funding was received for this study.

\section{Conflicts of interest}

Two authors report an affiliation with the journal's editorial team. The authors played no role in the peer-review process and subsequent editorial decisions related to this manuscript. The authors have no other conflicts to declare.

\section{References}

1. Mitchell BG, Gardner A. Addressing the need for an infection prevention and control framework that incorporates the role of surveillance: a discussion paper. $J$ Adv Nurs 2014; 70(3): 533-42. doi:10.1111/jan. 12193
2. Cosgrove S, Qi Y, Kaye K, Harbarth S, Karchmer A, Carmeli Y. The impact of methicillin resistance in Staphylococcus aureus bacteremia on patient outcomes: mortality, length of stay, and hospital charges. Infect Control Hosp Epidemiol 2005; 26(2): 166-74. doi:10.1086/ 502522

3. de Kraker ME, Wolkewitz M, Davey PG, Grundmann H. Clinical impact of antimicrobial resistance in European hospitals: excess mortality and length of hospital stay related to methicillin-resistant Staphylococcus aureus bloodstream infections. Antimicrob Agents Chemother 2011; 55(4): 1598-605. doi:10.1128/AAC.01157-10

4. Mitchell B, Wilson F, McGregor A, Dancer S. Methods to evaluate environmental cleanliness in healthcare facilities. Healthc Infect 2013; 18(1): 23-30. doi:10.1071/HI12047

5. Huang SS, Platt R. Risk of methicillin-resistant Staphylococcus aureus infection after previous infection or colonization. Clin Infect Dis 2003; 36(3): 281-5. doi:10.1086/345955

6. Dancer SJ. Hospital cleaning in the 21st century. Eur J Clin Microbiol Infect Dis 2011; 30(12): 1473-81. doi:10.1007/s10096-011-1250-x

7. Hayden MK, Bonten MJ, Blom DW, Lyle EA, van de Vijver DA, Weinstein RA. Reduction in acquisition of vancomycin-resistant Enterococcus after enforcement of routine environmental cleaning measures. Clin Infect Dis 2006; 42(11): 1552-60. doi:10.1086/503845

8. Hardy KJ, Oppenheim BA, Gossain S, Gao F, Hawkey PM. A study of the relationship between environmental contamination with methicillin-resistant Staphylococcus aureus (MRSA) and patients' acquisition of MRSA. Infect Control Hosp Epidemiol 2006; 27(2): 127-32. doi:10.1086/500622

9. Cooper RA, Griffith CJ, Malik RE, Obee P, Looker N. Monitoring the effectiveness of cleaning in four British hospitals. Am J Infect Control 2007; 35(5): 338-41. doi:10.1016/j.ajic.2006.07.015

10. Huang SS, Datta R, Platt R. Risk of acquiring antibiotic-resistant bacteria from prior room occupants. Arch Intern Med 2006; 166(18): 1945-51. doi:10.1001/archinte.166.18.1945

11. Rutala WA, Weber DJ. Role of the hospital environment in disease transmission, with a focus on Clostridium difficile. Healthc Infect 2013; 18(1): 14-22. doi:10.1071/HI12057

12. Sundararajan V, Henderson T, Perry C, Muggivan A, Quan H, Ghali WA. New ICD-10 version of the Charlson comorbidity index predicted in-hospital mortality. J Clin Epidemiol 2004; 57(12): 128894. doi:10.1016/j.jclinepi.2004.03.012

13. National Health and Medical Research Council. Australian Guidelines for the Prevention and Control of Infection in Healthcare (2010). Canberra; 2010.

14. Mitchell BG, Digney W, Locket P, Dancer SJ. Controlling methicillinresistant Staphylococcus aureus (MRSA) in a hospital and the role of hydrogen peroxide decontamination: an interrupted time series analysis. BMJ Open 2014; 4(4). doi:10.1136/bmjopen-2013-004522

15. Boyce JM, Potter-Bynoe G, Chenevert C, King T. Environmental contamination due to methicillin-resistant Staphylococcus aureus: possible infection control implications. Infect Control Hosp Epidemiol 1997; 18(9): 622-7. doi:10.2307/30141488

16. Bures S, Fishbain JT, Uyehara CF, Parker JM, Berg BW. Computer keyboards and faucet handles as reservoirs of nosocomial pathogens in the intensive care unit. Am J Infect Control 2000; 28(6): 465-71. doi:10.1067/mic.2000.107267

17. Sexton T, Clarke P, O'Neill E, Dillane T, Humphreys $\mathrm{H}$. Environmental reservoirs of methicillin-resistant Staphylococcus aureus in isolation rooms: correlation with patient isolates and implications for hospital hygiene. J Hosp Infect 2006; 62(2): 187-94. doi:10.1016/j.jhin.2005.07.017

18. Rabinowitz RP, Kufera JA, Makley MJ. A hidden reservoir of methicillin-resistant Staphylococcus aureus and vancomycin-resistant Enterococcus in patients newly admitted to an acute rehabilitation 
hospital. $P M \&$ \&: the journal of injury, function, and rehabilitation 2012; 4(1): 18-22. doi:10.1016/j.pmrj.2011.09.011

19. French GL, Otter JA, Shannon KP, Adams NM, Watling D, Parks MJ. Tackling contamination of the hospital environment by methicillinresistant Staphylococcus aureus (MRSA): a comparison between conventional terminal cleaning and hydrogen peroxide vapour decontamination. J Hosp Infect 2004; 57(1): 31-7. doi:10.1016/ j.jhin.2004.03.006

20. Russo P, Pittet D, Grayson L. Australia: a leader in hand hygiene. Healthc Infect 2012; 17(1): 1-2. doi:10.1071/HI12012

21. Mitchell B, McGregor A, Wells A, Wilson F. Tasmanian Acute Public Hospitals Healthcare Associated Infection Surveillance Report No.16. In Tasmanian Infection Prevention \& Control Unit, ed. Hobart: Department of Health and Human Services; 2013.

22. Shaughnessy MK, Micielli RL, DePestel DD, Arndt J, Stachan C, Welch K, Chenoweth C. Evaluation of Hospital Room Assignment and Acquisition of Clostridium difficile Infection. Infect Control Hosp Epidemiol 2011; 32(3): 201-6. doi:10.1086/658669

23. Drees M, Snydman DR, Schmid CH, Barefoot L, Hansjosten K, Vue P, Cronin M, Nasraway S, Golan Y. Prior environmental contamination increases the risk of acquisition of vancomycin-resistant enterococci. Clin Infect Dis 2008; 46(5): 678-85. doi:10.1086/527394

24. Nseir S, Blazejewski C, Lubret R, Wallet F, Courcol R, Durocher A. Risk of acquiring multidrug-resistant Gram-negative bacilli from prior room occupants in the intensive care unit. Clin Microbiol Infect 2011; 17(8): 1201-8. doi:10.1111/j.1469-0691.2010.03420.x

25. van Velzen EVH, Reilly JSP, Kavanagh KP, Leanord A, Edwards G, Girvan E, Gould I, MacKenzie F, Masterton R. A Retrospective Cohort Study into Acquisition of MRSA and Associated Risk Factors after Implementation of Universal Screening in Scottish Hospitals. Infect Control Hosp Epidemiol 2011; 32(9): 889-96. doi:10.1086/661280

26. Köck R, Winner K, Schaumburg F, Jurke A, Rossen JW, Friedrich AW. Admission prevalence and acquisition of nasal carriage of meticillin-resistant Staphylococcus aureus (MRSA) in German rehabilitation centres. $J$ Hosp Infect 2014; 87(2): 115-8. doi:10.1016/ j.jhin.2014.02.007

27. Barnett AG, Beyersmann J, Allignol A, Rosenthal VD, Graves N, Wolkewitz M. The time-dependent bias and its effect on extra length of stay due to nosocomial infection. Value Health 2011; 14(2): 381-6. doi:10.1016/j.jval.2010.09.008

28. Mitchell BG, Gardner A, Barnett AG, Hiller JE, Graves N. The prolongation of length of stay because of Clostridium difficile infection. Am J Infect Control 2014; 42(2): 164-7. doi:10.1016/j.ajic. 2013.07.006

29. Lasseter G, Charlett A, Lewis D, Donald I, Howell-Jones R, McNulty CA. Staphylococcus aureus carriage in care homes: identification of risk factors, including the role of dementia. Epidemiol Infect 2010; 138(5): 686-96. doi:10.1017/S0950268810000233 